\title{
JUS BUAH BERBASIS BIT MERAH (Beta vulgaris) PENAMBAHAN NANAS SMOOTH CAYENNE (Ananas comosus (L) merr.) SEBAGAI PANGAN FUNGSIONAL BAGI PENDERITA HIPERTENSI
}

\author{
Fruit Juice Based On Red Bit (Beta vulgaris) Addition Pineapple Smooth \\ Cayenne (Ananas comosus (L) merr.) As A Functional Food For Hypertension \\ Patients \\ Safarotul Magfiroh ${ }^{1}$, Maryam Razak ${ }^{1}$ \\ ${ }^{1}$ Jurusan Gizi Politeknik Kesehatan Kemenkes Malang \\ Email: maryamrazak0811@gmail.com
}

\begin{abstract}
ABSTRAK
Hipertensi merupakan peningkatan tekanan darah sistol, yang tingginya tergantung umur individu yang terkena. Bit merah (Beta vulgaris) merupakan salah satu sayuran kaya akan nitrat anorganik, senyawa antioksidan betalain, asam folat, riboflavin, dan kalium. Kalium dan asam folat memiliki peran penting dalam proses mengatur tekanan darah. Penambahan nanas bertujuan untuk mengurangi aroma tanah pada bit merah. Selain itu, nanas juga mengandung kalium dan vitamin $\mathrm{C}$ yang mampu membantu menurunkan tekanan darah. Tujuan penelitian ini adalah untuk mengetahui mutu organoleptik, kadar kalium dan aktivitas antioksidan jus bit merah (Beta vulgaris) dengan penambahan nanas smooth cayenne (Ananas comosus $(L)$ merr.) bagi penderita hipertensi. Penelitian ini merupakan penelitian RAL (Rancangan Acak Lengkap) dengan tiga taraf perlakuan, yaitu perbandingan bit merah dengan nanas, P1 (100:37.5), P2 (100:50) dan P3 (100:62.5). Analisis mutu organoleptik secara dekriptif dan Kruskal Wallis dengan uji lanjut Mann Whitney. Uji kalium menggunakan uji Spektometri dan Uji aktivitas antioksidan menggunakan Spektometri DPPH dan dikonversikan ke $\mathrm{IC}_{50}$. Analisis mutu kimia menggunakan One-way ANOVA dengan uji lanjut Duncan Multiple Range Test. Hasil penelitian menunjukkan bahwa penambahan nanas smooth cayenne memberikan pengaruh signifikan pada mutu organoleptik jus. Daya terima panelis terhadap mutu organoleptik jus (aroma, rasa dan warna) cenderung disukai. Kadar kalium jus meningkat rata-rata 468-1128 mg/100ml, aktivitas antioksidan jus rata-rata berkekuatan lemah sampai sedang (166.9-101.4 $\mu \mathrm{g} / \mathrm{ml})$. Taraf perlakuan terbaik adalah P3. Diperlukan penelitian lebih lanjut terhadap penggunaan bonggol nanas, untuk menambah kadar antioksidan, dan diperlukan penambahan nanas atau jenis buah lain untuk meningkatkan daya terima jus.

Kata Kunci: Jus bit merah (Beta vulgaris), Nanas Smooth Cayenne (Ananas comosus (L) Merr.), Mutu Organoleptik, Kadar Kalium, Aktivitas Antioksidan, Taraf perlakuan terbaik.
\end{abstract}

\section{ABSTRACT}

Hypertension is an increase in systolic blood pressure, the height of which depends on the age of the individual affected. Red beet (Beta vulgaris) is one of the vegetables rich in inorganic nitrate, betalain, folic acid, riboflavin and potassium antioxidant compounds. Potassium and folic acid play an important role in the process of regulating blood pressure. The addition of pineapple aims to reduce the smell of the soil in red beets. In addition, pineapple also contains potassium and vitamin $C$ which can 
help lower blood pressure. The purpose of this study was to determine the organoleptic quality, potassium levels and antioxidant activity of red beet juice (Beta vulgaris) by adding smooth cayenne pineapple (Ananas comosus (L) merr.) To patients with hypertension. This research is a RAL study (Completely Randomized Design) with three levels of treatment, namely the ratio of red bits to pineapple, P1 (100: 37.5), P2 (100: 50) and P3 (100: 62.5). Organoleptic quality analysis descriptively and Kruskal Wallis with Mann Whitney follow-up. Potassium test using the Spectometry test and the antioxidant activity test using DPPH Spectometry and converted to IC50. Chemical quality analysis using One-way ANOVA with Duncan's Multiple Range Test. The results showed that the addition of smooth cayenne pineapple had a significant influence on the quality of organoleptic juices. The panelists' acceptance of organoleptic quality of juice (smell, taste and color) tends to be favored. The level of potassium juice increased by an average of $468-1128 \mathrm{mg} / 100 \mathrm{ml}$, the antioxidant juice activity on average was weak to moderate $(166.9-101.4 \mu \mathrm{g} / \mathrm{ml})$. The best treatment level is P3. Further research is needed on the use of pineapple humps, to increase antioxidant levels, and the addition of pineapple or other types of fruit is needed to increase the acceptability of juice.

Keywords: Red beet juice (Beta vulgaris), Cayenne Smooth Pineapple (Ananas comosus (L) Merr.), Organoleptic Quality, Potassium Level, Antioxidant Activity, Best Treatment Level.

\section{PENDAHULUAN}

Hipertensi dapat disebabkan oleh berbagai faktor diantaranya obesitas, kebiasaan merokok, asupan natrium dan lemak jenuh dalam jumlah besar, konsumsi alkohol secara berlebihan, gaya hidup sedentary (banyak duduk), stres, renin berlebihan, defisiensi mineral serta diabetes mellitus (Kowalak, et al., 2003). Hipertensi merupakan faktor risiko terjadinya penyakit jantung koroner, stroke, penyakit ginjal, dan retinopati.

Karanja, et al (2007) menemukan bahwa studi tentang DASH (The Dietary Approaches to Stop Hypertension) merekomendasikan peningkatan konsumsi kalium melalui konsumsi buah, sayuran, ikan, dan kacang-kacangan, penggunaan produk susu rendah lemak, dan menurunkan intake lemak jenuh total, diiringi dengan penurunan intake sodium. Dauchet dan colleages (2007), meyatakan bahwa semakin tinggi konsumsi buahbuahan dan sayuran dalam DASH diet berhubungan dengan kontrol jangka panjang tekanan darah sistol selama 5 tahun.

Menurut Febry (2014) konsumsi sayur dan olahan serta buah-buahan dan olahan yang belum memadai berpengaruh terhadap suplai vitamin dan mineral yang dibutuhkan oleh tubuh. Buah dan sayur mengandung vitamin dan mineral, serat makanan, dan zat-zat phytochemical yang diperlukan tubuh. Tanpa vitamin dan mineral, proses pemanfaatan zat gizi yang dikonsumsi tidak dapat optimal. Phytochemical antara lain merupakan 
antioksidan yang sangat penting untuk tubuh dan mempunyai pengaruh untuk kesehatan. Antioksidan adalah pelindung sel tubuh agar tidak rusak oleh radikal bebas.

Bit merah (Beta vulgaris) merupakan salah satu sayuran yang didalamnya ditemukan berbagai senyawa penting. Hord dan Bryan (2009) menemukan bahwa bit merah (Beta vulgaris) kaya akan nitrat anorganik dengan kandungan $250 \mathrm{mg} / 100$ gr buah mentah. Bit merah (Beta vulgaris) juga memiliki senyawa antioksidan betalain yang tinggi, asam folat, riboflavin, kaya akan mineral sehingga bit merah (Beta vulgaris) juga bersifat isotonik (Bastanta, dkk., 2017). Betalain merupakan salah satu senyawa larut air serta antioksidan yang baik untuk stress oksidatif dan inflamasi. Pigmen merah-keunguan betaxantin dalam bit juga merupakan salah satu agen detoksifikasi yang baik bagi tubuh. Aktivitas antioksidan betalain lebih besar dibandingkan vitamin $\mathrm{C}$ dan polifenol. (Bryan dan Pierini, 2013). Kadar kalium dan asam folat didalam bit memiliki peran penting dalam proses mengatur tekanan darah (Rizki, 2013). Bit mengandung $325 \mathrm{mg}$ kalium per $100 \mathrm{~g}$ buah mentah (USDA, 2016). Meskipun demikian, bit merah masih kurang disukai oleh masyarakat umum akibat rasa langu (earthy taste) yang dimilikinya. Oleh karena itu, diperlukan bahan pangan yang memiliki rasa manis dan segar untuk mengurangi rasa yang tidak disukai.

Penambahan nanas jenis smooth cayenne dalam produk pangan ini digunakan untuk mengurangi rasa tanah (earthy taste) yang dimiliki bit merah (Beta vulgaris). Nanas umumnya memiliki rasa manis dan segar, mengandung kalium dan vitamin $\mathrm{C}$ yang mampu membantu menurunkan tekanan darah. Menurut Budiman dan Destina (2014), dalam $300 \mathrm{ml}$ jus nanas smooth cayene (Ananas comosus (L.) merr.) mengandung $130 \mathrm{mg}$ kalium dan $43.8 \mathrm{mg}$ vitamin $\mathrm{C}$.

Adanya kandungan kalium, antioksidan pada bit dan nanas diharapkan menjadi salah satu pilihan minuman selingan dalam bentuk jus bagi penderita hipertensi.

\section{METODE PENELITIAN}

Penelitian ini menggunakan jenis penelitian eksperimen laboratorium dengan desain penelitian Rancangan Acak Lengkap (RAL) menggunakan 3 taraf perlakuan yaitu perbandingan antara bit dan nanas P1 (100:37.5), P2 (100:50) dan P3 (100:62.5) dengan formulasi 
berdasarkan DASH diet dalam Mc Fall et al. (2010), yaitu menekankan pada konsumsi bahan makanan rendah natrium (<2300 mg/hari), tinggi kalium (4700 $\mathrm{mg} /$ hari), magnesium $(>420$ $\mathrm{mg} /$ hari), kalsium(>1000 mg/hari), dan serat $(25-30 \mathrm{~g} / \mathrm{hari})$ serta rendah asam lemak jenuh dan kolesterol $\quad(<200$ mg/hari) dengan modifikasi kalium berdasarkan $30 \%$ kecukupan kalium perhari, yakni $1410 \mathrm{mg}$. Masing-masing taraf perlakuan dilakukan 3 kali pengulangan.

\section{HASIL DAN PEMBAHASAN}

\section{Mutu Organoleptik}

\section{Aroma}

Berdasarkan hasil uji mutu organoleptik dua puluh panelis agak terlatih dengan tingkat penerimaan panelis dengan skala likert 1-4 (sangat tidak sukasangat suka) terhadap aroma jus buah berkisar antara 2-3 (tidak suka-suka). Diketahui bahwa semakin besar penambahan proporsi nanas smooth cayenne tingkat kesukaan panelis meningkat. Tingkat kesukaan tertinggi pada perlakuan P3 (100:62.5), persentase suka sebesar $70 \%$. Aroma jus pada taraf perlakuan ini disukai panelis karena aroma normal khas nanas yang dominan. Menurut Winarno (1993) buah nanas mempunyai aroma yang khas yaitu sedikit asam dan sebagian besar aroma nanas disebabkan oleh senyawa 2,5 dimetil-4hidroksi-3(2H)-furanon.

Berdasarkan analisis statistik Kruskall Wallis menunjukkan bahwa penambahan proporsi nanas smooth cayenne memberikan pengaruh yang signifikan terhadap aroma jus buah nilai $\mathrm{P}_{\text {value }}<0.05$ (0.002). Hasil uji post hoc Mann Whitney dengan nilai $\mathrm{P}_{\text {value }}<0.05$ menunjukkan bahwa penambahan proporsi nanas smooth cayenne memberikan pengaruh signifikan pada aroma taraf perlakuan $\mathrm{P} 1$ tehadap taraf perlakuan lainnya.

\section{Rasa}

Hasil penelitian menunjukkan bahwa semakin besar penambahan proposi nanas smooth cayenne semakin meningkat kesukaan panelis. Tingkat kesukaan tertinggi pada perlakuan P3 (100:62.5), persentase suka sebesar 65\%. Rasa jus pada taraf perlakuan ini disukai panelis karena berasa manis sedikit asam. Rasa manis sedikit asam pada jus diduga berasal dari nanas. Menurut Agoes (2010) nanas memiliki rasa yang sedikit asam dikarenakan adanya kandungan asam sitrat, asam malat, dan asam aspartat. Selain itu, Okonkwo, et al (2012) 
menyatakan nanas memiliki kandungan gula berupa glukosa dan fruktosa yang merupakan karbohidrat dan sumber rasa manis.

Berdasarkan analisis statistik Kruskall Wallis dengan $\alpha=0.05$ menunjukkan bahwa penambahan proporsi nanas smooth cayenne memberikan pengaruh yang signifikan terhadap rasa jus buah $\left(\mathrm{P}_{\text {value }}<0.05\right)$. Hasil uji post hoc menggunakan Mann Whitney dengan nilai $\alpha=0.05$ menunjukkan bahwa aroma taraf perlakuan P1 berbeda secara signifikan tehadap taraf perlakuan lainnya $\left(\mathrm{P}_{\text {value }}<0.05\right)$.

\section{Warna}

Berdasarkan hasil uji mutu organoleptik diketahui bahwa semakin besar penambahan proporsi nanas smooth cayenne memberikan pengaruh pada tingkat kesukaan panelis. Secara keseluruhan Warna jus buah dominan merah keunguan pekat. Warna merah keunguan yang kuat dan pekat berasal dari kandungan betasianin yang merupakan turunan dari betalain yaitu pigmen berwarna merah atau merah-violet dalam buah bit merah (Andersen dan Markham, 2006). Stintzing, et al., (2008) menyatakan bahwa betasianin merupakan pigmen utama yang ada di dalam umbi bit merah (Beta vulgaris ) (75\%-95\% betanin). Menurut Mastuti (2010) betasianin dari buah bit (Beta vulgaris) diketahui memiliki efek antiradikal dan aktivitas antioksidan yang tinggi.

Berdasarkan hasil analisis statistik Kruskall Wallis dengan $\quad \alpha=0.05$ menunjukkan bahwa penambahan proporsi nanas smooth cayenne memberikan pengaruh yang signifikan terhadap warna jus buah. Hasil uji post hoc menggunakan Mann Whitney dengan tingkat kepercayaan $95 \% \quad(\alpha=5 \%)$ menunjukkan bahwa penambahan proporsi nanas smooth cayenne (Ananas comosus (L) merr.) memberikan pengaruh signifikan pada aroma taraf perlakuan P1 dan $\mathrm{P} 2$. $\left(\mathrm{P}_{\text {value }}<0.05\right)$.

\section{Kadar kalium}

Sitanggang (2013) menyatakan bahan pangan yang mengandung kalium baik dikonsumsi penderita tekanan darah tinggi. Kebutuhan kalium diperkirakan sebesar $2000 \mathrm{mg} /$ hari. Jhondry (2010) dalam Maria, dkk., (2012) bahwa peningkatan asupan kalium dapat menurunkan tekanan darah, penurunan tekanan darah ini dapat dikarenakan adanya penurunan resistensi vaskular akibat dilatasi pembuluh darah serta adanya peningkatan kehilangan air dan 
natrium dari tubuh hasil aktivitas pompa bagian ekstraseluler dan menurunkan natrium dan kalium). Banyak tekanan darah (Feby, 2013). Berikut ini mengonsumsi kalium akan meningkatkan (Tabel 1) rata-rata kadar kalium dalam jus konsentrasi di dalam cairan intraseluler bit merah-nanas.

sehingga cenderung menaikkan cairan di

Tabel 1. Rata-rata Kadar Kalium dalam Jus Bit Merah (Beta vulgaris) Penambahan Nanas Smooth Cayenne (Ananas comosus (L) Merr.)

\begin{tabular}{cc}
\hline $\begin{array}{c}\text { Taraf Perlakuan Proporsi (\%) } \\
\text { (bit merah : nanas) }\end{array}$ & Rata-rata kadar kalium (mg) \\
\hline $\mathrm{P}_{1}(100: 37.5)$ & $468^{\mathrm{a}}$ \\
$\mathrm{P}_{2}(100: 50)$ & $1.128^{\mathrm{a}}$ \\
$\mathrm{P}_{3}(100: 62.5)$ & $906^{\mathrm{a}}$ \\
\hline
\end{tabular}

Huruf yang berbeda menunjukkan perbedaan yang signifikan $(\alpha=0.05)$

Berdasarkan Tabel 1 dapat terdapat dalam tubuh kita yaitu senyawa diketahui bahwa semakin besar proporsi yang dapat menetralkan radikal bebas, penambahan nanas smooth cayenne seperti enzim SOD (Superoksida meningkatkan kadar kalium jus buah. Dismutase), gluthatione, dan katalase. Camara, et al (1995) menyebutkan bahwa Radikal bebas merupakan atom atau kalium merupakan salah satu mineral molekul yang memiliki elektron bebas utama dari jus nanas segar. Alifah (2011), yang tak berpasangan. Elektron yang tidak rata-rata kadar kalium pada buah nanas berpasangan cenderung akan menarik masak adalah $737,92 \mathrm{mg} / \mathrm{Kg}$.

Berdasarkan hasil analisis statistik elektron dari senyawa lainnya, sehingga One Way Anova dengan $\alpha=0.05$ elektron tersebut akan dimiliki bersama menunjukkan bahwa penambahan oleh dua atom atau senyawa dan terbentuk proporsi nanas smooth cayenne tidak senyawa radikal bebas baru yang lebih memberikan pengaruh yang signifikan reaktif. Reaktivitas yang meningkat terhadap kadar kalium jus buah $\left(\mathrm{P}_{\mathrm{value}}>\alpha\right)$.

\section{Aktivitas antioksidan}

Prakash (2001) menyebutkan antioksidan merupakan senyawa yang tersebut menyebabkan senyawa radikal bebas menjadi lebih mudah untuk menyerang sel-sel sehat dalam tubuh. Menurut Uppu, Murthy, Pryor, dan Parinadi, (2010) menyatakan bahwa jika pertahanan tubuh lemah maka sel-sel 
tersebut menjadi sakit atau rusak (Uppu, antioksidan alami, seperti rempah-rempah, Murthy, Pryor, dan Parinadi, 2010). coklat, biji-bijian, buah-buahan, sayur-

Antioksidan dapat diperoleh dari sayuran seperti buah tomat, pepaya, jeruk, asupan makanan yang banyak dan sebagainya (Prakash, 2001). Berikut mengandung vitamin $\mathrm{C}$, vitamin $\mathrm{E}$ dan ini rata-rata aktivitas antioksidan dalam betakaroten serta senyawa fenolik. Bahan jus bit merah dan nanas disajikan pada pangan yang dapat menjadi sumber Tabel 2.

Tabel 2. Rata-rata Aktivitas Antioksidan Jus Bit Merah (Beta vulgaris) dengan Penambahan Nanas Smooth Cayenne (Ananas comosus (L) Merr.)

\begin{tabular}{cc}
\hline $\begin{array}{c}\text { Taraf Perlakuan Proporsi }(\%) \\
\text { (Bit merah : nanas) }\end{array}$ & $\begin{array}{c}\text { Rata-rata Aktivitas } \\
\text { Antioksidan } \\
(\boldsymbol{\mu g} / \mathbf{m L})\end{array}$ \\
\hline $\mathrm{P}_{1}(100: 37.5)$ & $166.900^{\mathrm{b}}$ \\
$\mathrm{P}_{2}(100: 50)$ & $163.067^{\mathrm{b}}$ \\
$\mathrm{P}_{3}(100: 62.5)$ & $101.467^{\mathrm{a}}$
\end{tabular}

Huruf yang berbeda menunjukkan adanya perbedaan signifikan $(\alpha=0.05)$

Berdasarkan Tabel 2 diketahui asetat yang terkandung dalam sari bahwa penambahan nanas dapat bonggol, kulit, daging buah nenas meningkatkan nilai aktivitas antioksidan merupakan senyawa flavonoid yang jus buah. Semakin besar proporsi nanas mudah melepaskan proton (hydrogen) smooth cayenne yang ditambahkan sehingga memiliki kemampuan yang baik aktivitas antioksidan jus buah semakin dalam menangkal radikal bebas. meningkat. Taraf perlakuan dengan Berdasarkan analisis statistik aktivitas antioksidan tertinggi adalah P3 menggunakan uji One Way ANOVA dengan penambahan nanas smooth dengan $\alpha=0.05$ menunjukkan bahwa cayenne sebesar 250 gr memiliki aktivitas penambahan proporsi nanas smooth antioksidan sebesar $101.467 \mu \mathrm{g} / \mathrm{mL}$ cayenne memberikan pengaruh yang (sedang). Hasil penelitian Sadeli (2016) signifikan terhadap aktivitas jus bit merah menunjukkan bahwa ekstrak bromelin dan nanas, ditunjukkan dengan dalam daging buah nanas dengan nilai $\left(\mathrm{P}_{\text {value }}<0.05\right)$. Lebih lanjut, hasil uji $\mathrm{IC}_{50}$ sebesar $4.7221 \pm 0.0287 \mathrm{mg} / \mathrm{mL}$. Duncan Multiple Range Test Hampir serupa, penelitian Hayat, dkk menunjukkan bahwa taraf perlakuan P3 (2015) senyawa fenolik dalam fraksi etil berbeda signifikan dengan perlakuan P1 
dan P2, sedangkan taraf perlakuan P1 dan P2 tidak berbeda secara signifikan.

\section{Perlakuan terbaik}

Taraf perlakuan terbaik yaitu P3 diisajikan pada Tabel 3.

Tabel 3. Karakteristik Taraf Perlakuan Terbaik Jus Bit Merah dan Nanas

\begin{tabular}{lc}
\hline \multicolumn{1}{c}{ Karakteristik } & $\begin{array}{c}\text { Taraf perlakuan P3 } \\
\text { per sajian 200 ml }\end{array}$ \\
\hline Kadar kalium $(\mathrm{mg})$ & 1920 \\
Aktivitas & 101.467 \\
antioksidan $(\mu \mathrm{g} / \mathrm{mL})$ & aroma khas nanas \\
Aroma & Manis sedikit asam \\
Rasa & Merah keunguan \\
Warna & \\
\hline
\end{tabular}

Kerry dan Edward (2001), menyatakan kalium merupakan ion intraseluler dan dihubungkan dengan mekanisme pertukaran natrium. Peningkatan asupan kalium dalam diet telah dihubungkan dengan penurunan tekanan darah karena kalium memicu natriuresis yaitu dapat memicu kehilangan natrium lewat urin. Yaswir dan Ferawari (2012) kekurangan kalium dapat berefek buruk dalam tubuh karena mengakibatkan hypokalemia yang menyebabkan frekuensi denyut jantung melambat. Kelebihan kalium dapat mengakibatkan hyperkalemia yang menyebabkan aritmia jantung, konsentrasi yang lebih tinggi lagi yang dapat menimbulkan henti jantung atau fibrilasi jantung. Halim (2011) bahwa dengan konsumsi jus bit merah sebanyak $200 \mathrm{ml}$ mampu memberikan pengaruh terhadap penurunan tekanan darah.

Aktivitas antioksidan pada Jus bit merah dan nanas pada taraf perlakuan P3 sebesar $101.467 \mu \mathrm{g} / \mathrm{mL}$ (sedang). Taraf perlakuan P3 merupakan taraf perlakuan dengan penambahan nanas tertinggi, yakni 250 gr. Aktivitas antioksidan pada perlakuan ini lebih tinggi dari kedua taraf perlakuan sebelumnya hal ini diduga akibat adanya kandungan antioksidan di dalam nanas. Aktivitas antioksidan pada nanas bersumber dari senyawa polifenol dan asam askorbat (Hossain dan Rahman, 2010). Berdasarkan hasil penelitin Lugas dan Hóvári (2003) kandungan total polifenol dalam buah nanas segar sebesar $36.2 \pm 0.5$ GAE/100 mL. Selain itu, berdasarkan hasil penelitian Hayat dkk. (2015) diketahui bahwa senyawa fenolik dalam nanas (meliputi bonggol, daging buah dan kulit) mengandung senyawa flavonoid yang mudah melepaskan atom hydrogen dan memiliki kemampuan yang baik untuk menangkal radikal bebas.

Freedman, et al, (2001) menyatakan bahwa flavonoid dapat menurunkan tekanan darah karena merupakan derivate polifenol dari diphenylpans, merupakan senyawa yang hanya ditemukan pada 
tumbuh- tumbuhan. Senyawa ini dalam menurunkan tekanan darah tinggi mempunyai efek atheroprotektif yang pada penderita hipertensi.

meliputi efek antioksidan yang kuat, meningkatkan kemampuan platelet untuk melepaskan NO dan menghambat pembentukan trombus. Peningkatan NO akan mengakibatkan vasodilatasi pembuluh darah yang akhirnya akan menyebabkan turunnya tekanan darah. Hal ini sesuai dengan penelitian yang dilakukan oleh Erlund et. al,( 2008) yang mengatakan bahwa polifenol seperti pada pada flavonoid berkaitan dengan aktivitas antioksidan kuat, hambatan agregasi platelet, dan fungsi endoterial sehingga terjadi penurunan tekanan darah. Dayanthi dkk, (2010) Kandungan antioksidan yang cukup dapat membantu meningkatkan pertahanan tubuh terhadap timbulnya penyakit yang disebabkan oleh radikal bebas. Namun, apabila dikonsumsi berlebihan justru dapat menimbulkan penyakit karena dapat menyebabkan penimbunan lemak.

Jus bit merah dan nanas ini disarankan untuk dikonsumsi sebanyak $200 \mathrm{ml}$ per hari. Jus sebaiknya dikonsumsi pada waktu selingan, pagi atau sore. Kandungan mineral berupa kalium, nitrat dan antioksidan didalamnya diharapkan mampu membantu memberikan pengaruh

\section{KESIMPULAN}

1. Penambahan nanas smooth cayenne (Ananas comosus (L) merr.) memberikan pengaruh yang signifikan terhadap parameter mutu aroma, rasa dan warna pada jus. Penambahan proporsi nanas smooth cayenne (Ananas comosus (L) merr.) menyebabkan aroma, rasa dan warna jus disukai oleh panelis.

2. Penambahan nanas smooth cayenne (Ananas comosus (L) merr.) tidak memberikan pengaruh yang signifikan terhadap kadar kalium pada jus.

3. Penambahan nanas smooth cayenne (Ananas comosus (L) merr.) memberikan pengaruh yang signifikan terhadap aktivitas antioksidan pada jus buah.

4. Taraf perlakuan terbaik adalah P3 (100:62.5).

\section{SARAN}

Diperlukan penelitian lebih lanjut terhadap penggunaan bonggol nanas, untuk meningkatkan kadar antioksidan, dan diperlukan penambahan nanas atau jenis buah lain untuk meningkatkan daya terima jus buah. 


\section{DAFTAR PUSTAKA}

Agoes, A. 2010. Tanaman Obat Indonesia. Jakarta: Salemba Medika

Alifah, Cholifatul Umi. 2011. Analisis kadar kalium pada nanas (Ananas Comosus (L) Merr) muda dan masak. JTPTUNIMUS

Andersen, M., Markham, K.R. 2006. Flavonoids. New York: Taylor \& Francis Group.

Armala, M. M.,. 2009. Daya Antioksidan Fraksi Air Ekstrak Herba Kenikir (Cosmos caudatuc HBK) dan Profil KLT, Skripsi, Fakultas Farmasi UII, Yogyakarta.

Bastanta, D., dkk., 2017. Pengaruh perbandingan sari sirsak dengan sari bit dan konsentrasi gula terhadap sirup sabit. Jurnal Rekaysa Pangan dan Pertanian. 5 (1) : 102-108.

Bryan, S. Nathan., Pierini, Carolyn. 2013. Beet the Odds : Harness the Power of Beetroots to Radically Transform Your Health. USA.

Budiman, Iwan dan Destina, Tria. 2014. Efek Nanas (Ananas comosus (L.) Merr.) Terhadap Penurunan Tekanan Darah Tahun 2014.
Camara, M.; Diez, C.; Torija, E.1995. Chemical characterization of pineapple juices and nectars.Principal components analysis. Food Chem., 54, 93-100.

Dauchet, L dan Colleages. 2007. Dietary patterns and blood pressurechange over 5-y follow up in the SU. VI. MAX cohort. Am J Clin Nutr 85 (6) : 1650-1656.

Erlund I., Koli R., Alfthan G., Marniemi J., Puukka P., Mustonen P., et al. 2008. Favorable effects of berry consumption on platelet function, blood pressure, and HDL cholesterol. Am J Clin Nutr, 87: 323-331, Mei 2018

Febry, Ayu Bulan K. D. 2014. Jus \& infused water buah-sayuran ampuh tumpas penyakit, awet muda, dan langsing. Jakarta : Loveable.

Freedman, J.E., Parker, C., Li, L. et al,. 2001. Select Flavonoids and Whole Juice From Purple Grapes Inhibit Platelet Fuction and Enhanced Nitric Oxide Release. Circulation, 103 : 2792, Mei 2018

Halim SS. Pengaruh Jus Beet (Beta vulgaris L.) terhadap Tekanan Darah. Skripsi. Bandung: Fakultas 
Kedokteran Universitas Kristen Marantha. 2011.

Hayat, I.U, dkk. 2015. Pengaruh sari buah nanas (Ananas comosus (L.) terhadap aktivitas antioksidan pada ekstrak tongkol jagung (Zea mays 1.). Jurnal Ilmiah FantasiUNSRAT, 3 (4), Agustus 2015.

Hord N. G., Tang Y., Bryan N. S. 2009. Food Sources of Nitrates and Nitrites: The Physiologic Context for Potential Health Benefits. The American Journal of Clinical Nutrition. 90 (1) :1-10.

Hossain, M. A an d M. M.A. Rahman. 2011. Total Phenoli Cs, Flavonoids And Antioxidant Activity Of Tropical Fruit Pineapple. Food Res. Int. 44: 672-676.

Kerry J and D Ledward. Meat Processing. New York: CRC press. 2001.

Kowalak, Jennifer $\mathrm{P}$ et al. 2003. Buku Ajar Patofisiologi. Diterjemahkan oleh dr. Andy Hartono. Penerbit Buku Kedokteran EGC : Jakarta.

Maria, Genilda. dkk. 2012. Hubungan Asupan Natrium dan Kalium dengan Tekanan Darah pada Pasien Hipertensi di Unit Rawat Jalan di Rumah Sakit Guido Valadares Dili Timor Leste. Prodi
Ilmu Gizi, Fakultas Kesehatan

Universitas Respati Yogyakarta.

Mastuti. 2010. Identifikasi Pigmen Betasianin Pada Beberapa Jenis Inflorescence Celosia, J. Bio., Yogyakarta.

McFall JM, Barkley JE, Gordon KL, Burzsminski N, Glickman EL. 2010. Effect of the DASH Diet on Pre- and Stage 1 Hypertensive Individuals in a Free-Living Environment. Nutrition and Metabolic Insights. 3 (15-23).

Okonkwo, S.I, R.U, Ogbuneke dan B.K., Uyo. 2012. Elucidation of Sugar in Edible Fruit-Pineapple (Ananas Comosus). Reserch Journal of Chemical Sciences, 2 (20-22), Januari 2012.

Prakash, A., Rigelhof, F., dan Miller, E., 2001. Antioxidant Activity : Medallion Laboratories, Analithycal Progress. 19 (2): 1-4.

Rizki, Farah. 2013. The Miraacle of Vegetables. Jakarta : Agromedia Pustaka.

Rohman, A., Riyanto. 2005. Aktivitas Antioksidan Ekstrak Buah Mengkudu (Morinda Citrifolia L,). Agritech, 25 (3) :131-136.

Sitanggang, S. S. Penetapan kadar kalsium, kalium, dan natrium 
dalam buah nanas (Ananas

comosus (L.) Merr.) Cayenne

secara spektrofotometri serapan

atom. 2013. Skripsi. Medan:

Universitas Sumatera Utara.

Stintzing, F.C., Herbach, M. R.

Mosshammer, F. Kugler, and R.

Carle. 2008. Betalain Pigments and Color Quality.

Yaswir, R., \& Ferawati, I. 2012. Fisiologi dan gangguan keseimbangan natrium, kalium dan klorida serta pemeriksaan laboratorium. Jurnal Kesehatan Andalas,1(2), 78-84 